| Dossiê: Impactos e Repercussões Socioambientais de Empreendimentos na Pan-Amazônia | DOI: http://dx.doi.org/10.18764/2446-6549.202007

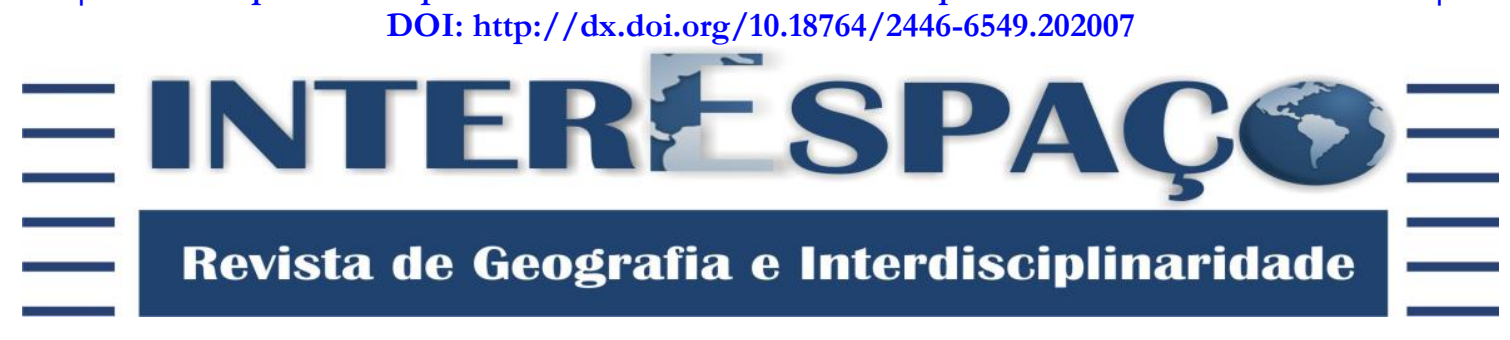

\title{
IMPLANTAÇÃO DA FÁBRICA DE CELULOSE DA SUZANO NO SUDOESTE MARANHENSE À LUZ DOS PRINCÍPIOS DO DESENVOLVIMENTO SUSTENTÁVEL
}

\section{IMPLEMENTATION OF THE SUZANO PULP MILL IN THE SOUTHWEST OF MARANHÃO IN THE LIGHT OF THE PRINCIPLES OF SUSTAINABLE DEVELOPMENT}

\author{
IMPLEMENTACIÓN DE LA FÁBRICA DE CELULOSA SUZANO EN \\ SUROESTE DE MARANHÃO A LA LUZ DE LOS PRINCIPIOS DE \\ DESARROLLO SOSTENIBLE
}

\begin{abstract}
Gabriel Nava Lima
Doutor pelo Programa de Pós-Graduação em Meio Ambiente e Desenvolvimento Regional da Universidade Anhanguera - Uniderp. Professor do Centro Universitário Estácio São Luís. gabrielnaval@gmail.com / http://orcid.org/0000-0002-8062-8644
\end{abstract}

\section{Ademir Kleber Morbeck de Oliveira}

Doutor em Ciências pela Universidade Federal de São Carlos - UFSCar. Professor do Programa de Pós-Graduação em Meio Ambiente e Desenvolvimento Regional da Universidade Anhanguera -

$$
\text { akmorbeckoliveria@gmail.com / http://orcid.org/0000-0001-9373-9573 }
$$

Recebido para avaliação em 25/06/2020; Aceito para publicação em 10/11/2020.

\section{RESUMO}

O Estado brasileiro fez diversos investimentos na área de infraestrutura e financiou empreendimentos que criaram condições para a expansão do agronegócio e surgimento de empreendimentos industriais, em detrimento do extrativismo e da agricultura de subsistência na região centro-sul do estado do Maranhão nos últimos 50 anos. Uma das empresas a se estabelecer foi a Suzano Papel e Celulose, que no início do século XXI modificou sua estratégia de negócio, passando a investir na produção de celulose para a exportação. Dentro desse novo contexto, o sudoeste maranhense passou a ser um local estratégico para a empresa, que atualmente possui uma Unidade de Negócio Florestal que administra uma fábrica de celulose e um Empreendimento de Manejo Florestal. Em vista dessa realidade, este trabalho se propôs analisar como a Suzano implementa os princípios do desenvolvimento sustentável dentro do contexto socioeconômico e fundiário da região. Metodologicamente, o trabalho é teórico-qualitativo e tem um viés exploratório, sendo a base da pesquisa a análise de material bibliográfico, imagens, relatórios e dados estatísticos produzidos pelo Estado brasileiro e pela empresa certificadora do empreendimento celulósico. Ao final, é possível indicar que a Suzano usou o discurso de desenvolvimento sustentável para convencer as comunidades que seu polo celulósico não causaria grandes modificações nas bases sociais locais. Entretanto, os resultados demonstram que a empresa abdicou dos princípios norteadores da sustentabilidade e da responsabilidade social e ambiental, quando confrontada com possíveis perdas econômicas.

Palavras-chave: Agronegócio; Silvicultura; Empreendimento de Manejo Florestal; Responsabilidade Social e Ambiental; Suzano Papel e Celulose. 


\title{
| Gabriel Nava Lima | Ademir Kleber Morbeck de Oliveira |
}

\begin{abstract}
The Brazilian State has made several investments in the area of infrastructure and financed enterprises that created conditions for the expansion of agriculture and the emergence of industrial enterprises, to the detriment of extractivism and subsistence agriculture in the central-southern region of the state of Maranhão, over the past 50 years. One of the companies to be established was Suzano Papel e Celulose, which at the beginning of the 21 st century, modified its business strategy, and started investing in celulose production, for exportation. Within this new context, the southwest of Maranhão became a strategic location for the company, which currently has a Forestry Business Unit that manages a pulp mill and a Forest Management Enterprise. In view of this, this work analyzes how Suzano implements the principles of sustainable development within the socioeconomic and land context of the region. Methodologically, the work is theoretical and qualitative with an exploratory bias, being the base of the research the analysis of bibliographic material, images, reports and statistical data produced by the Brazilian State and by the certifying company of cellulosic enterprise. In the end, it is possible to indicate that Suzano used the sustainable development discourse to convince communities that its cellulosic pole would not cause major changes in the local social bases. However, the results demonstrate that the company has abdicated the guiding principles of sustainability and social and environmental responsibility, when faced with possible economic losses.
\end{abstract}

Keywords: Agribusiness; Forestry; Forest Management Enterprise; Social and Environmental Responsibility; Southwest of Maranhão; Suzano Papel e Celulose.

\section{RESUMEN}

El Estado brasileño ha realizado varias inversiones en el área de infraestructura y ha financiado empresas que crearon condiciones para la expansión de los agronegocios y el surgimiento de empresas industriales, en detrimento de la extractivismo y la agricultura de subsistencia en la región centro-sur del Maranhão en los últimos 50 años. Una de las empresas que se estableció fue Suzano Papel e Celulose, que a principios del siglo XXI modificó su estrategia comercial, comenzando a invertir en la producción de celulosa para exportación. Dentro de este nuevo contexto, el suroeste de Maranhão se convirtió en una ubicación estratégica que actualmente cuenta con una Unidad de Negocio Forestal que administra una fábrica de celulosa y una Empresa de Manejo Forestal. En vista de esta realidad, este trabajo tuvo como objetivo analizar cómo Suzano implementa los principios del desarrollo sostenible dentro del contexto socioeconómico y territorial de la región. Metodológicamente, el trabajo es teórico y cualitativo y tiene un sesgo exploratorio, siendo la base de la investigación el análisis de material bibliográfico, imágenes, informes y datos estadísticos producidos por el Estado y por la empresa certificadora de la empresa celulósica. Al final, es posible indicar que Suzano utilizó el discurso del desarrollo sostenible para convencer a las comunidades de que su polo celulósico no causaría cambios importantes en las bases sociales locales. Sin embargo, los resultados demuestran que la empresa ha abdicado de los principios rectores de sostenibilidad y responsabilidad social y ambiental ante posibles pérdidas económicas.

Palabras clave: Agronegocios; Silvicultura; Empresa de Gestión Forestal; Responsabilidad Social y Ambiental; Suzano Papel e Celulose.

\section{INTRODUÇÃO}

A região sudoeste do estado do Maranhão passa por um crescimento econômico acelerado, impulsionado pelo agronegócio. A sojicultura e a silvicultura redefiniram a forma de uso e ocupação do solo e transformaram a estrutura fundiária da região, com a pequena propriedade sendo substituída por grandes propriedades voltadas para a produção de commodities agrícolas. 
| Implantação da fábrica de celulose da Suzano no sudoeste maranhense à luz dos princípios do desenvolvimento sustentável|

| Gabriel Nava Lima | Ademir Kleber Morbeck de Oliveira |

O processo de expansão da sojicultura na área do MATOPIBA - acrônimo usado para designar áreas ligadas ao agronegócio nos estados do Maranhão, Tocantins, Piauí e Bahia - alcançou o sul e sudoeste maranhense no início da década de 1990 e transformou uma área pobre, cuja economia girava em torno da pecuária extensiva e da pequena propriedade agrícola, em um centro gerador de riquezas. A sojicultora transformou o sul do Maranhão "num espaço nacional de economia internacional” (SANTOS, 1996, p. 244).

A Suzano Papel e Celulose S.A. também expandiu sua presença no sudoeste maranhense. A empresa já atuava na região leste desde a década de 1980, fazendo pesquisa e produzindo eucalipto para a produção de carvão. Todavia, na primeira década do século XXI, a empresa redefiniu sua estratégia para o mercado de celulose ao implantar o "Plano Suzano 2024", cujo objetivo era - e ainda é - expandir sua produção para exportação. Dentro desse novo contexto, a região passou a ser um local estratégico para produzir e depois escoar a celulose produzida (STPC, 2010).

A construção da planta fabril na cidade de Imperatriz e do terminal portuário Grandis em São Luís, capital do estado, fazem parte do "Plano Suzano 2024”. Também faz parte do plano estratégico a criação, ainda em 2010, do Projeto Florestal localizado na região do município de Porto Franco, para suprir a demanda por matéria-prima da Unidade de Produção de Celulose. No RIMA (Relatório de Impacto Ambiental) do Projeto Florestal é dito que a base florestal poderá ser implantada em 21 municípios (STCP, 2010).

O processo de implantação de grandes projetos estatais na Amazônia Legal foi estudado pela academia em diversas áreas do saber, com trabalhos que tratam especificamente do uso e ocupação do solo no estado do Maranhão. Brasil (1984), Porro, Mesquita \& Santos (2004), Ferreira (2006), Ferreira (2008), Santos (2011), Andrade (2012), Oliveira \& Ribeiro Júnior (2013), Ribeiro Júnior et al. (2014), Pantoja \& Pereira (2016) e Marques (2016), dentre outros, analisaram o uso e ocupação do espaço maranhense. Porém a forma como aconteceu - e como está acontecendo - a ocupação do sudoeste do estado pela Suzano Papel e Celulose S.A. foi pouco estudada.

Buscando ampliar o conhecimento sobre essa temática, o presente trabalho se propõe analisar como a Suzano Papel e Celulose implementa os princípios do desenvolvimento sustentável dentro do contexto socioeconômico e fundiário da região na segunda década do século XXI.

\section{MATERIAL E MÉTODOS}


| Implantação da fábrica de celulose da Suzano no sudoeste maranhense à luz dos princípios do desenvolvimento sustentável|

| Gabriel Nava Lima | Ademir Kleber Morbeck de Oliveira |

A metodologia utilizada foi a qualitativa, com a realização do levantamento de material bibliográfico, imagens e dados estatísticos produzidos pelo IBGE, com um viés exploratório. Também foram analisados os Relatórios de Auditoria Anual do Manejo das Plantações Florestais e da Cadeia de Custódia Desde a Floresta até a Saída do Produto da Empresa publicados pela SYSFLOR - Certificações Florestais (2013, 2014, 2015, 2016, 2017 e 2018), Plano de Governança Florestal da Unidade de Negócio Florestal Maranhão (2017), Relatórios de Sustentabilidade publicados pela Suzano (2014 e 2019), documentos de reuniões realizadas pela Suzano com as comunidades impactadas pelo projeto fabril e florestal e artigos acadêmicos que tratam do processo de ocupação do território no sudoeste maranhense. A partir dos dados coletados, o trabalho analisou, sob o prisma do desenvolvimento sustentável, o território ocupado pelo Empreendimento de Manejo Florestal da Suzano no sudoeste maranhense - controlado pela Unidade de Negócios Florestais da Suzano no Maranhão. As informações coletadas junto as fontes foram analisadas primeiro separadamente, buscando suas singularidades e depois cruzadas, objetivando esboçar um panorama geral e plural do processo de ocupação do território pelo Suzano Papel e Celulose.

\section{RESULTADOS E DISCUSSÃO}

\section{Território e a (Re)significação do uso do solo no sudoeste maranhense}

Figueiredo (2016, p. 12), ao analisar a formação territorial brasileira, afirma que a exploração dos recursos naturais está na raiz do processo de ocupação e desenvolvimento econômico do País. Eles foram importantes para acelerar o crescimento econômico em diversos momentos históricos, consolidando o mercado interno. Atualmente, são a base que sustenta a competitividade nacional no mercado de commodities agrícolas.

Até a década de 1990, discussões que versavam sobre reforma agrária, assentamento de pessoas, fim do latifúndio improdutivo, impactos do progresso tecnológico no campo e migrações eram a base das pesquisas ligadas a questão agrária no Brasil. A esses temas foram introduzidas discussões e iniciadas pesquisas ligadas às questões ambientais e a sustentabilidade. Dentro dessa nova realidade, foram inseridos temas relacionados a "agricultura familiar, a conformação dos mercados de trabalho e a dinâmica ocupacional da população rural” (SCHNEIDER, 2003, p. 100). A temática passou a ser discutida de forma multidisciplinar e seu escopo metodológico foi ampliado fazendo surgir novos objetos de estudo, tais como a ocupação do espaço. 
| Implantação da fábrica de celulose da Suzano no sudoeste maranhense à luz dos princípios do desenvolvimento sustentável|

| Gabriel Nava Lima | Ademir Kleber Morbeck de Oliveira |

Moreira (2012) diz que o homem se relaciona com a natureza a partir do trabalho. A forma como ele a usa para produzir é que caracteriza a definição de espaço. Para ele, a forma como se dá a ocupação de uma área pode definir o espaço como produto, meio de produção ou reprodução das relações sociais - socioculturais, econômicas e políticas. Neste sentido, Pires, Müller \& Verdi (2006, p. 448) afirmam que o desenvolvimento territorial traz na sua gênese uma mudança social de caráter endógeno, pois o território passa ser a base para o desenvolvimento econômico regional, uma vez que os agentes econômicos passam a traçar suas estratégias competitivas levando em consideração as vantagens locacionais que determinado território possui.

O Maranhão teve seu território ocupado a partir de ciclos econômicos que expandiram suas fronteiras regionais e moldaram sua formação socioeconômica. Becker (2001, p. 135) chama essa forma de ocupação territorial de economia de fronteira, "em que o progresso é entendido como crescimento econômico e prosperidade infinitos, baseados na exploração de recursos naturais percebidos como igualmente infinitos”.

Segundo Keller (1975, p. 672), a construção da rodovia Belém-Brasília (BR 010), foi o grande agente transformador do sudoeste maranhense. Além da rodovia, construída na década de 1970, outras obras de infraestrutura foram executadas com o objetivo de atrair empresas para a região sul do Maranhão e Pará.

Na década de 1980, dentro da estrutura do Projeto Grande Carajás, foi construída a

[...] estrada de Ferro Carajás, conectando a província mineral de Carajás (sudeste do Pará) ao litoral maranhense, focada no Complexo Portuário de São Luís, formado pelos Portos do Itaqui (dirigido pela Empresa Maranhense de Administração Portuária - EMAP), da Ponta da Madeira (de propriedade da Vale) e da ALUMAR, alimentando também oito usinas de processamento de ferro gusa às margens dessa estrada de ferro (RIBEIRO JUNIOR; OLIVEIRA; COSTA, 2014, p. 15).

Atualmente, a Suzano usa a estrutura logística da Vale para transportar a celulose produzida em Imperatriz até o Porto do Itaqui, em São Luís. Usando essa cadeia logística, há uma redução de tempo significativa entre o embarque da celulose, e a chegada na mesma nos mercados europeu e americano (5 dias). 
| Implantação da fábrica de celulose da Suzano no sudoeste maranhense à luz dos princípios do desenvolvimento sustentável|

| Gabriel Nava Lima | Ademir Kleber Morbeck de Oliveira |

Figura 1 - Localização do Projeto Florestal, Florestas da Suzano e da linha férrea ligando a cidade de

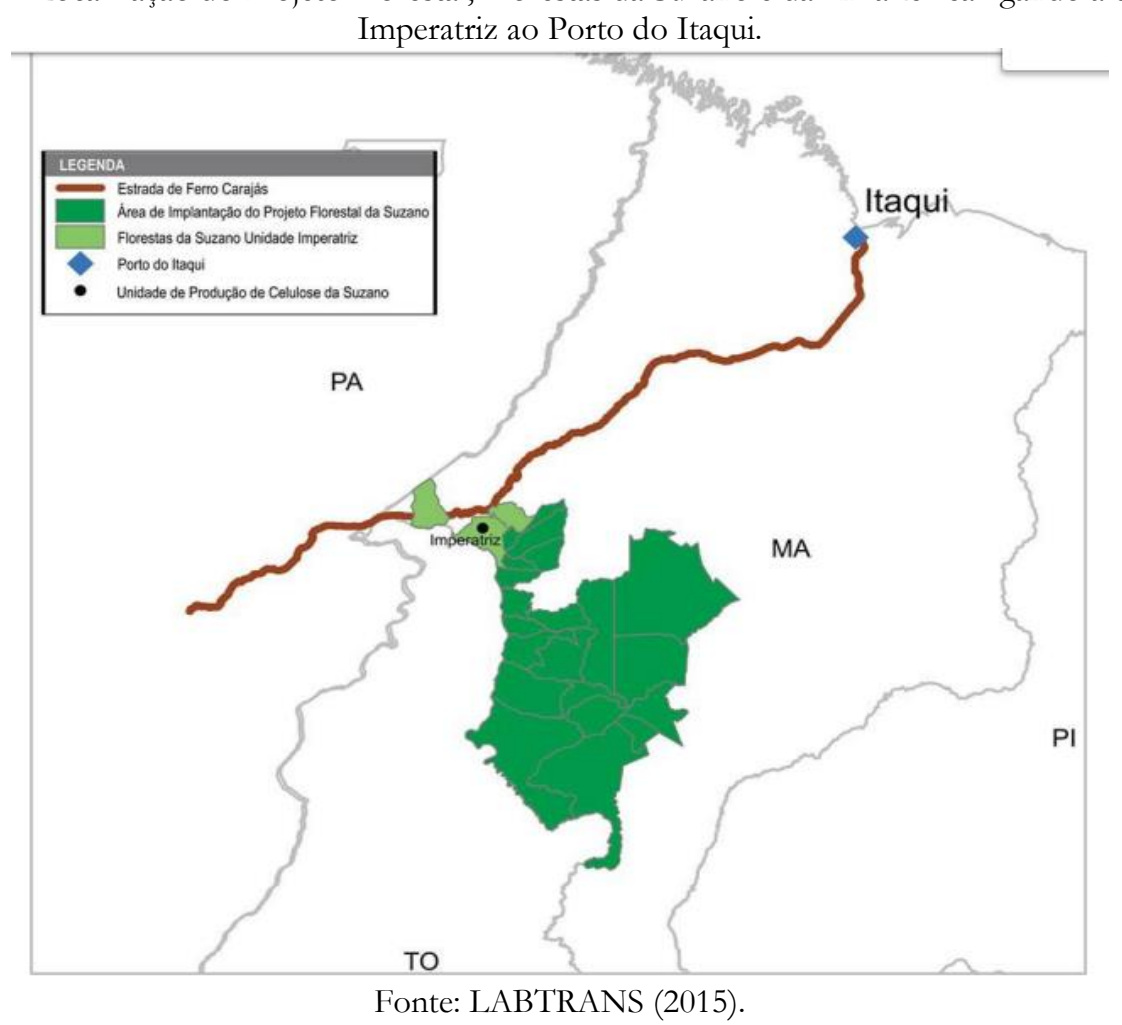

A expansão das fronteiras regionais na década de 1990, somada a infraestrutura criada pelo Estado, criou condições socioeconômicas propícias para a implantação do agronegócio voltado para produção de commodities agrícolas. Essa nova realidade transformou a forma de uso e ocupação do território que existia até então no sudoeste maranhense e redefiniu as bases econômicas da região. A agricultura de subsistência, a criação de gado de forma extensiva e o extrativismo deram lugar a grandes empreendimentos agrícolas.

Fernandes (2008, p. 279), ao discutir a categoria Território afirma que:

\begin{abstract}
Em suas diferentes acepções, o território sempre foi estudado a partir de relações de poder, desde o Estado ao capital, desde diferentes sujeitos, instituições e relações. $\mathrm{Na}$ essencialidade do conceito de território estão seus principais atributos: totalidade, multidimensionalidade, escalaridade e soberania. Portanto, é impossível compreender o conceito de território sem conceber as relações de poder que determinam a soberania.
\end{abstract}

A produção majoritária de commodities para o mercado externo - inicialmente a soja, e depois celulose - modificou as relações sociais e deu novo significado ao conceito de território e ao modelo de uso e ocupação do solo. A terra, antes vista como um meio para a produção de mercadorias, passou a ser também mercadoria, pois a venda das propriedades rurais passou a ser uma opção rentável em decorrência da valorização dos imóveis (SANTOS; TAVARES, 2016, p. 379). 
| Implantação da fábrica de celulose da Suzano no sudoeste maranhense à luz dos princípios do desenvolvimento sustentável|

| Gabriel Nava Lima | Ademir Kleber Morbeck de Oliveira |

Quando tratam dos motivos que levaram a Suzano a escolher a região sudoeste do Maranhão para a implantação de um polo celulósico, Oliveira, Pereira \& Nascimento (2018, p. 143) afirmam que:

\begin{abstract}
[...] as multiplicidades espaciais são vistas como vantagens competitivas. Os espaços são considerados a partir dos seus elementos, sobretudo locacionais. [...] Desta forma, cabe reiterar que a atividade industrial em questão necessita de grandes áreas de cultivo para o plantio de eucalipto que é utilizado na produção dos dois produtos principais: papel e celulose. A instalação no Maranhão veio sob uma lógica produtiva estratégica: áreas existentes com potencial de utilização e novas áreas destinadas ao cultivo da principal matéria-prima.
\end{abstract}

Seguindo essa mesma linha de pensamento, Ribeiro Júnior et al. (2014) afirmam que o valor venal da terra na região foi um dos fatores preponderantes para a expansão dos negócios da Suzano. Segundo os autores, o valor do hectare chegava a ser sete vezes mais barato que o praticado em São Paulo (sede da empresa). A nova demanda por terras inflacionou o valor dos imóveis rurais e modificou as relações de poder entre os atores sociais na área onde seria produzida a matéria-prima para a fábrica de celulose. Pequenos agricultores viram a venda de suas fazendas como uma possibilidade de transformação na sua condição social, e grandes proprietários, a possibilidade de enriquecimento rápido.

Ao implantar o parque fabril, a Suzano (re)significou o conceito de território e a forma de uso e ocupação do solo em toda a área de influência do empreendimento celulósico. Além de ampliar a concentração de terras, modificou a situação fundiária da região ao diminuir a quantidade de áreas destinadas à pecuária e à agricultura familiar. A agropecuária deu lugar a silvicultura e a pequena propriedade ao grande Empreendimento de Manejo Florestal.

\title{
O “desenvolvimento sustentável” do sudoeste maranhense
}

Até a década de 1970, as teorias econômicas que se propunham a estudar o modelo de desenvolvimento capitalista desconsideravam os componentes ambientais nas suas análises. O colapso dos recursos naturais, a poluição, ou a destruição dos ecossistemas não eram vistas como variáveis a serem levadas em consideração quando se pensava em modelos de desenvolvimento ou crescimento econômico (MIKHAILOVA, 2004, p. 23).

O conceito de sustentabilidade e desenvolvimento sustentável surgiram da percepção que o modelo de desenvolvimento econômico calcado na exploração sem controle dos recursos naturais era incompatível com a sobrevivência da espécie humana a longo prazo. 
| Implantação da fábrica de celulose da Suzano no sudoeste maranhense à luz dos princípios do desenvolvimento sustentável|

| Gabriel Nava Lima | Ademir Kleber Morbeck de Oliveira |

De acordo com Fialho et al. (2007, p. 149), a sustentabilidade está ligada à existência futura, à noção de perenidade, a algo que não se esgota. Neste sentido, quando se fala em desenvolvimento sustentável, está se falando de maneiras de produzir riquezas e desenvolvimento social a longo prazo, preservando o ambiente e os recursos renováveis.

Fernandez (2011, p. 117) afirma que o princípio que rege as ideologias ligadas ao desenvolvimento sustentável são as relações fundamentais de valores. As interações entre o sistema social, o meio ambiente e o sistema econômico devem priorizar a manutenção da biodiversidade a partir da sua capacidade de resiliência ecossistêmica em escala global. Nas palavras de Sachs (1981, p. 14), "trata-se de gerir a natureza de forma a assegurar aos homens de nossa geração e a todas as gerações futuras a possibilidade de se desenvolver".

O Estado Brasileiro, quando planejou a ocupação do sudoeste maranhense, desconsiderou os princípios de desenvolvimento sustentável em nome do crescimento econômico e ignorou os indivíduos que viviam na região. Rocha \& Mota (2012, p. 19), ao abordarem esse processo de ocupação afirmam:

É sabido que o agronegócio no sul maranhense encontra-se inserido nos grandes projetos de desenvolvimento do Estado e da expansão da fronteira agrícola, que avançou sobre os Cerrados principalmente na segunda metade do século XX com a ideologia de integração e unificação nacional, negando aí a existência e a importância dos grupos já estabelecidos nessas localidades.

Atualmente a expansão da fronteira agrícola não tem mais o objetivo de expandir a ocupação do território. A nova fronteira é vista como detentora de potencial econômico e político que deve ser explorado, porque o agronegócio une a noção de espaço geográfico à economia nacional e global a partir da produção e exportação de commodities.

Não restam dúvidas de que a produção de commodities é um grande negócio econômico, mas é possível fazer a seguinte indagação: para quem e para quantos, já que tem um alto custo social e ambiental?

Castillo (2015), ao comparar o Campo Tradicional com o Campo Moderno, demonstrou as diferenças do viver e vivenciar o trabalho nessas duas realidades antagônicas. No Campo Tradicional a população constrói as relações sociais e econômicas a partir da tradição, e a produção é voltada para o consumo local ou regional. O Campo Moderno é caracterizado pela presença de agricultores que constroem suas relações sociais a partir de padrões urbanos de convivência e trabalham o campo fazendo uso de máquinas modernas. Além disso, se caracteriza pela existência de agroindústrias; comerciantes e prestadores de serviços especializados no agrobusiness; empresas de compra e 
| Implantação da fábrica de celulose da Suzano no sudoeste maranhense à luz dos princípios do desenvolvimento sustentável|

\section{| Gabriel Nava Lima | Ademir Kleber Morbeck de Oliveira |}

arrendamento de terras; e, presença de agentes financeiros e toda uma gama de normas e regras ligadas à produção em larga escala.

A forma de uso e ocupação do solo também é diferente. No Campo Tradicional, a relação tem um cunho comunitário e ligado a ancestralidade, com uma relação intrínseca entre a população e uma porção do bioma. No Campo Moderno, a relação é de competição: a terra é vista como uma mercadoria que deve reunir as condições materiais para garantir alta produtividade e rentabilidade para determinados setores econômicos inseridos em mercados internacionais. Como as duas formas são opostas, a tendência é que o Campo Tradicional dê lugar ao Campo Moderno (CASTILLO, 2015).

Scott apud Menezes \& Malagodi (2011), falando especificamente da indústria de celulose, diz que o pequeno agricultor busca quase sempre evitar o risco de ampliação da sua produção por medo da ruína econômica. A lógica é simples. Ele vive à margem da subsistência e sua produção depende do clima e da demanda por seus produtos. Como essas duas variáveis não são controláveis, prefere não arriscar sua renda e propriedade.

Existe uma fronteira entre a reprodução dos processos de produção que não trazem risco e o cálculo de lucro. Quando o risco desaparece, a visão capitalista normalmente prevalece. A pressão feita pela indústria de celulose para comprar ou arrendar terras, somada ao fascínio que a vida urbana exerce sobre o morador do campo e a promessa de uma vida mais estável, leva o pequeno proprietário a abrir mão de suas terras e migrar para as cidades.

Essa afirmação é uma verdade na área impactada pelo complexo celulósico da Suzano no sudoeste maranhense. As promessas de transformação socioeconômica em sua área de influência, principalmente as ligadas à criação de emprego e renda, impulsionaram a migração do campo para cidade.

Pantoja \& Pereira (2016, p. 337), ao entrevistarem moradores de povoados impactados de forma direta ou indireta pelo projeto celulósico, sistematizaram da seguinte maneira os problemas socioambientais surgidos durante e após o processo de implantação da fábrica da Suzano:

Sistematizando os principais impactos causados pela empresa, segundo as falas de nossos informantes, é possível pensar, em pelo menos três formas:

1) Impactos ambientais caracterizados pelas mudanças nos cursos e qualidade da água dos córregos, eliminação dos resíduos da unidade industrial da empresa Suzano, tráfego intenso e constante de caminhões durante o dia e a noite;

2) Impactos na forma de organização comunitária, já que também foi relatada a ocorrência de assédio, por parte da empresa, sobre associações e indivíduos, práticas individualistas, falta de confiança em determinados membros da comunidade com função de mediação entre as comunidades e a empresa; e, 
| Implantação da fábrica de celulose da Suzano no sudoeste maranhense à luz dos princípios do desenvolvimento sustentável|

| Gabriel Nava Lima | Ademir Kleber Morbeck de Oliveira |

3) Impactos nas formas de produção, visto que se restringe o acesso à terra tornando, com isso, inviável a relação de produção direta com a terra, ou seja, a condição de camponês ou lavrador, termo mais utilizado pelos moradores, fica ameaçada.

O complexo celulósico da Suzano trouxe crescimento econômico para a região, ocorreu um crescimento real do PIB per capita e os indicadores sociais melhoram. Todavia, não se pode afirmar que existiu desenvolvimento econômico ou sustentável capaz de modificar a estrutura social de forma permanente.

\section{A expansão "sustentável" da Suzano no sudoeste maranhense a partir da análise} dos relatórios da SysFlor Certificações de Manejo e Produtos Florestais

Ciofi (2010, p. 17) afirma que nas organizações, o conceito de sustentabilidade está ligado a três princípios: Governança Corporativa, Responsabilidade Social e Ambiental. Segundo o autor, as empresas devem planejar suas ações de forma a utilizar de maneira eficiente e responsável os recursos disponíveis de modo a gerenciar os impactos no ambiente, estabelecendo uma relação harmoniosa entre os funcionários, gerando riqueza com menos danos socioambientais e "prestando contas à todas as classes relacionadas a sua operação".

No site oficial da Suzano é dito que ela "entende sustentabilidade como a capacidade de permitir que os ciclos de crescimento se renovem, o que implica construir as bases para uma expansão que integre operações competitivas, responsabilidade socioambiental e relacionamentos de qualidade" (SUZANO, 2020). De acordo com o site, é esse conceito que norteia as políticas de responsabilidade corporativa da empresa, pois ela busca sempre a harmonização entre "geração de valor e dignidade humana".

A forma como a Suzano explicita sua visão de sustentabilidade e como coloca em prática esse conceito pode ser analisado sob a ótica de duas teorias da gestão de organizações: a Teoria da Legitimidade e a Teoria dos Stakeholders.

Lindblom (2010), quando discute os objetivos de uma organização que busca legitimidade para existir em determinado ambiente, escreve que ela:

a) Mantém seu público interno e externo informado sobre temas negativos ligados à sua atividade. Fazendo isso, reconhece perante seu público que não pode apresentar-se neutra e imparcial diante de temas negativos relacionados às suas atividades;

b) Não muda seu desempenho empresarial, ela muda a forma como o ambiente em que está inserida a percebe. Ela busca evidenciar que sua produção, métodos e objetivos estão de acordo com as normas existentes no ambiente em que opera; 
| Implantação da fábrica de celulose da Suzano no sudoeste maranhense à luz dos princípios do desenvolvimento sustentável|

| Gabriel Nava Lima | Ademir Kleber Morbeck de Oliveira |

c) Manipula o público ao não comentar assuntos que podem ser danosos a sua imagem. Para tanto, a organização coloca em evidencia e enfatiza ações positivas realizadas no passado que legitimam sua existência no ambiente onde opera; e,

d) Muda seu discurso junto ao público externo quando ele percebe que há discrepância entre a produção, métodos e objetivos apresentados pela organização quando se instalou no ambiente e a realidade de momento. Ela não faz ajustes internos, ela ajusta as expectativas do seu público acenando com melhorias no desempenho futuro.

Freeman \& Mcvea (2000, p. 2) definem a Teoria dos Stakeholders como

[...] a formulação e implementação, pelos administradores, de processos que satisfaçam todos os grupos que tenham interesses em jogo na empresa. A principal tarefa nesse processo seria gerenciar e integrar os relacionamentos e os interesses de acionistas, funcionários, clientes, fornecedores, comunidades e outros grupos, de modo a assegurar o sucesso da empresa a longo prazo.

As duas teorias se complementam e ajudam a entender os motivos que levam as organizações a divulgarem balanços sociais e relatórios de sustentabilidade. A divulgação desses e de outros documentos tem por objeto garantir as exigências de transparência e responsabilidade social do cenário econômico e manter uma linha de comunicação com os agentes que de forma direta ou indireta estão envolvidos com a organização: sociedade, governo, ambiente e investidores, por exemplo.

De acordo com o "Relatório da Avaliação para Recertificação de Manejo Florestal e Cadeia de Custódia desde a Floresta até a Saída do Produto da Empresa”, produzido pela SYSFLOR Certificações de Manejo e Produtos Florestais, a Suzano Papel e Celulose possuía 246.514,97 ha de terras no sudoeste maranhense, distribuídos por 18 municípios no ano de 2018 (SYSFLOR, 2018) (Tabela 1).

A SYSFLOR é a empresa responsável pela certificação FSC® e pela certificação CERFLOR do Empreendimento de Manejo Florestal (EMF) da Suzano Papel e Celulose S.A. Ela é a responsável pela elaboração do "Relatório de auditoria anual do manejo das plantações florestais e da cadeia de custódia desde a floresta até a saída do produto da empresa" e pela elaboração do "Relatório da avaliação para recertificação de manejo florestal e cadeia de custódia desde a floresta até a saída do produto da empresa”.

Toda a matéria-prima que é produzida pelo EMF deve, necessariamente, ser avaliada e depois certificada pela SYSFLOR. As informações contidas nos relatórios produzidos pela certificadora são públicas e os certificados concedidos servem como garantia para o mercado e para os consumidores finais de que a Suzano é uma empresa sustentável e produz seguindo os princípios da responsabilidade social e ambiental. 
| Implantação da fábrica de celulose da Suzano no sudoeste maranhense à luz dos princípios do desenvolvimento sustentável|

| Gabriel Nava Lima | Ademir Kleber Morbeck de Oliveira |

Tabela 1 - Municípios do sudoeste maranhense e seu perfil socioeconômico onde a Suzano Papel e Celulose possui terras próprias ou arrendadas oficialmente

\begin{tabular}{|c|c|c|c|c|}
\hline Cidade & $\begin{array}{l}\text { População } \\
\text { 2019* }\end{array}$ & $\begin{array}{c}\text { Pessoal } \\
\text { ocupado* }\end{array}$ & $\begin{array}{l}\text { Renda média } \\
\text { em salários } \\
\text { mínimos* }\end{array}$ & $\begin{array}{c}\text { População com rendimento } \\
\text { nominal até } 1 / 2 \text { salário } \\
\text { mínimo** }\end{array}$ \\
\hline Açailândia & 112.445 & $14,5 \%$ & 2,0 & $43,4 \%$ \\
\hline Cidelândia & 14.697 & $5,5 \%$ & 2,3 & $46,5 \%$ \\
\hline Estreito & 41.946 & $8,8 \%$ & 2,0 & $39,2 \%$ \\
\hline $\begin{array}{l}\text { Feira Nova do } \\
\text { Maranhão }\end{array}$ & 8.504 & $5,1 \%$ & 1,6 & $57,9 \%$ \\
\hline $\begin{array}{l}\text { Governador } \\
\text { Edison Lobão }\end{array}$ & 18.296 & $10,1 \%$ & 1,7 & $42,5 \%$ \\
\hline Grajaú & 69.527 & $9,3 \%$ & 1,9 & $48,6 \%$ \\
\hline Itinga & 26.000 & $9,8 \%$ & 1,8 & $47,8 \%$ \\
\hline Imperatriz & 258.682 & $22,8 \%$ & 2,0 & $37,4 \%$ \\
\hline João Lisboa & 23.632 & $7,0 \%$ & 1,6 & $45,5 \%$ \\
\hline Porto Franco & 23.885 & $11,1 \%$ & 2,2 & $41,9 \%$ \\
\hline Riachão & 20.195 & $6,5 \%$ & 1,8 & $52,5 \%$ \\
\hline Ribamar Fiquene & 7.791 & $6,9 \%$ & 1,7 & $47,4 \%$ \\
\hline $\begin{array}{c}\text { São Francisco do } \\
\text { Brejão }\end{array}$ & 11.798 & $3,6 \%$ & 2,0 & $48,8 \%$ \\
\hline $\begin{array}{c}\text { São João do } \\
\text { Paraíso }\end{array}$ & 11.177 & $7,0 \%$ & 1,9 & $52,1 \%$ \\
\hline $\begin{array}{l}\text { São Pedro dos } \\
\text { Crentes }\end{array}$ & 4.668 & $8,0 \%$ & 1,6 & $50,8 \%$ \\
\hline $\begin{array}{l}\text { São Pedro da } \\
\text { Água Branca }\end{array}$ & 12.690 & $4,5 \%$ & 1,8 & $46,9 \%$ \\
\hline Sítio Novo & 18.081 & $6,6 \%$ & 1,8 & $57,7 \%$ \\
\hline $\begin{array}{c}\text { Vila Nova dos } \\
\text { Martírios }\end{array}$ & 13.392 & $8,3 \%$ & 2,3 & $46,9 \%$ \\
\hline
\end{tabular}

Fonte: IBGE. *Números referentes ao ano de 2017. **Censo 2010.

O perfil econômico dos municípios onde a Suzano já se instalou demonstra que:

a) Em 16 deles, no mínimo 40\% da população vive com até meio salário mínimo mensal;

b) Somente quatro possuem mais de $10 \%$ da população ocupada formalmente e com renda média mensal dos trabalhadores formais de 2,0 salários mínimos; e,

c) Com exceção de Imperatriz, os maiores empregadores da região são os próprios municípios e o governo do Maranhão.

Diante da realidade socioeconômica desses municípios, a chegada da Suzano na região trouxe consigo a possibilidade de mudança na estrutura social, principalmente porque a empresa afirmou que ocuparia o território buscando harmonizar a geração de valor com a melhoria da qualidade de vida das pessoas que viveriam no entorno do seu EMF, tal como é explicitado no site da empresa.

Este discurso criou expectativas, mas a análise dos relatórios produzidos pela SYSFLOR entre os anos de 2013 e 2018 demonstram que a Suzano, até aquele momento, 
| Implantação da fábrica de celulose da Suzano no sudoeste maranhense à luz dos princípios do desenvolvimento sustentável|

| Gabriel Nava Lima | Ademir Kleber Morbeck de Oliveira |

não implantara de forma consistente seu conceito de sustentabilidade nas comunidades onde possuía florestas plantadas.

No relatório de auditoria anual de 2016, a SYSFLOR relata que a Suzano apoiou, quando da implantação do EMF na macrorregião de Porto Franco (2010/2011), projetos ligados ao desenvolvimento da agricultura familiar - implantação de hortas comunitárias e o desenvolvimento da atividade de apicultura - mas, que deixou de incentivá-los em 2013, sem propor nenhum outro plano de ação ligado à responsabilidade social na região (SYSFLOR, 2016, p. 46).

O relatório de auditoria de 2017 traz uma explicação da empresa para a ausência de projetos sociais criados ou apoiados na área sob sua influência. Nele é dito que a Suzano está "aguardando definição de estratégia para implantação de projetos sociais na região (definição de prioridades, demandas e potenciais sociais, para desenvolvimento local)" (SYSFLOR, 2017, p. 31).

De acordo com o relatório

Para investimentos em projetos de interesse social nas regiões de sua atuação, a empresa estabeleceu como estratégia um novo processo de desenvolvimento territorial participativo, através da implantação de Conselhos Comunitários voltados para definição de temas prioritários pelas comunidades e de potenciais parceiros (SYSFLOR, 2017, p. 31).

Os Conselhos Comunitários foram idealizados, segundo a Suzano, com o objetivo de envolver mais diretamente as comunidades localizadas no entorno de suas propriedades e operações. O processo de implantação dos Conselhos teve início em 2015, mas as primeiras experiências fizeram a empresa rever a estratégia de implantação dos mesmos e realinhar as expectativas que foram criadas pelo seu público interno e pelas comunidades envolvidas (SYSFLOR, 2018, p. 59).

A suspensão dos projetos sociais gerou descontentamento nas comunidades. Para não perder a legitimidade adquirida, e não ser vista como um organismo estranho ao ambiente, a Suzano fez uso de alguns dos princípios da Teoria da Legitimidade de Lindblom (2010).

A empresa não modificou sua forma de atuar na região. Ela realinhou sua estratégia de convivência com as comunidades reajustando as expectativas criadas pelas mesmas e acenando com melhorias no futuro. No relatório da SYSFLOR de 2018 há uma explicação dada pela Suzano para a necessidade da implantação dos Conselhos Comunitários antes da criação de projetos sociais: 
| Implantação da fábrica de celulose da Suzano no sudoeste maranhense à luz dos princípios do desenvolvimento sustentável|

| Gabriel Nava Lima | Ademir Kleber Morbeck de Oliveira |

Os conselhos comunitários são uma estratégia da Suzano para discutir de forma coletiva os investimentos na região direcionados para comunidades, mobilizando lideranças, agentes públicos e comunitários para debater a realidade local e encontrar soluções conjuntas (SYSFLOR, 2018, p. 59).

A ideia de envolver a maior quantidade de Stakeholders quando da seleção de projetos de interesse social é importante e vai de encontro à teoria de Stakeholder de Freeman e Mcvea (2000). Mas a análise dos relatórios deixa claro que a Suzano não apoiou nenhum projeto de desenvolvimento social que garantisse emprego e renda de forma permanente na região durante os anos de 2014, 2015, 2016, 2017 e 2018. É dito no relatório que a seleção dos projetos - não a implementação - só começaria a ser feita em 2018.

No Relatório de Sustentabilidade de 2019 (SUZANO, 2020), publicado no final de abril de 2020, a Suzano diz que começou a implantar no Maranhão, sem especificar a região, o Programa de Desenvolvimento Rural Territorial (PDRT).

\footnotetext{
Lançado em 2012, o PDRT tornou-se um programa amplamente reconhecido por potencializar as atividades rurais de cada território com o apoio na forma de assistência técnica em três eixos: gestão, produção e comercialização das associações e das cooperativas participantes (SUZANO, 2020, p. 69).
}

Novamente a aplicação dos princípios da teoria da legitimidade Lindblom (2010) pode ser percebida quando a empresa anuncia a implantação do PDRT. Desde 2014 a Suzano não implantava programas sociais capazes de gerar emprego e renda na região e os Conselhos Comunitários, que seriam criados pela empresa para definir em quais comunidades seriam beneficiadas, não foram efetivamente implantados. Essa realidade fez surgir descontentamentos nas comunidades existentes no entorno do EMF. Para minimizar os impactos negativos ligados a imagem da empresa, foi criado o PDRT.

Novamente o discurso ligado a implantação de programas geradores de emprego e renda foi usado para ajustar as expectativas das comunidades quanto a ação da empresa, acenando com melhorias no desempenho futuro.

A Suzano também faz uso da teoria da legitimidade Lindblom (2010) quando não explica por que a implantação dos Conselhos foi suspensa. Ela coloca em evidência a criação de um novo programa social, o PDRT, e não comenta a suspensão. Dito de outra forma: a Suzano não comenta um tema capaz de arranhar a imagem da empresa junto à comunidade e coloca em evidencia e enfatiza a criação de um novo programa social para legitimar sua existência na região. 
| Implantação da fábrica de celulose da Suzano no sudoeste maranhense à luz dos princípios do desenvolvimento sustentável|

| Gabriel Nava Lima | Ademir Kleber Morbeck de Oliveira |

Também é possível perceber, a partir da análise dos relatórios de avaliação e de auditoria da SYSFLOR, que o Empreendimento de Manejo Florestal não cumpriu de forma sistêmica os preceitos da responsabilidade ambiental.

No relatório de avaliação de 2013, é dito que a Suzano possuía recursos materiais adequados para combater incêndios,

[...] porém em termos de treinamento, verificou-se deficiência do conteúdo programático que não destaca procedimentos de segurança da equipe para situações críticas, como incêndios em grotas, incêndios em morro acima, condições da vegetação do local de incêndio, etc.) (SYSFLOR, 2013, p. 56).

As deficiências do treinamento aparecem até nos EPI's usados pela equipe: "Foi observado que as camisas usadas pelos componentes das brigadas que combatem incêndios é confeccionada com material sintético (67\% poliéster e 33\% viscose), não compatível com o risco da atividade de combate a incêndio" (SYSFLOR, 2013, p. 57).

Uma outra passagem no relatório de 2013 explicita ainda mais o descaso da empresa com relação a sua responsabilidade ambiental. Nela é dito que "não foi evidenciada a existência de um plano para o mapeamento ou a demarcação dos habitats das espécies endêmicas, raras e ameaçadas de extinção” (SYSFLOR, 2013, p. 45).

No relatório de auditoria de 2014 é dito que o EMF do Maranhão identificou 8 áreas de relevante interesse ecológico por serem consideradas locais de floresta nativa. Porém, a observação in loco feita pelos certificadores constatou que elas eram constituídas por subáreas de vegetação em estágio de regeneração (SYSFLOR, 2014, p. 31).

Também foi constatado pela equipe de certificadores que o Empreendimento de Manejo Florestal estava fazendo uso de fogo para realizar parte do manejo florestal.

A empresa está utilizando fogo em casos específicos (redução de resíduos, redução de risco de incêndios etc.) na UMF, conforme verificado no Bloco São Bento. No PMF da empresa, item 6.4.3, descreve-se que o EMF ‘*...+não adota o uso do fogo, como técnica de manejo, mesmo se permitido por lei.', em discordância com o observado nas inspeções de campo. Além disso, evidenciouse que a empresa não possui autorização dos órgãos competentes para executar (SYSFLOR, 2014, p. 32).

No relatório de auditoria de 2015, a certificadora chama atenção outra vez para falhas no treinamento dos responsáveis pelo controle e monitoramento dos EMF.

Foi verificado que o EMF não monitora o programa de treinamento que as EPS desenvolvem com seus colaboradores. Foram observados conteúdos programáticos repetidos para "cursos diversos" e carga horária incompatível com a abrangência do conteúdo proposto. Ex. curso de primeiros socorros com carga horária de 4 h e curso de combate a incêndio florestal, com carga horária 
| Implantação da fábrica de celulose da Suzano no sudoeste maranhense à luz dos princípios do desenvolvimento sustentável|

| Gabriel Nava Lima | Ademir Kleber Morbeck de Oliveira |

de 8 h. Foram observados cursos com o mesmo conteúdo programático registrado (procedimentos operacionais de silvicultura, meio ambiente/flora e fauna, disposição de resíduos, etc.), sem que o conteúdo tenha relação direta com o tema do curso (SYSFLOR, 2015, p. 47).

Em decorrência das falhas encontradas no Empreendimento de Manejo Florestal quando da auditoria realizada em 2014, e a persistência dos problemas na auditoria de 2015, a certificadora é direta quanto a capacidade da Unidade de Negócios Florestais em implementar o Plano de Manejo Florestal do EMF:

A empresa apresenta dificuldade de implementação de seu plano de manejo em função do quadro restrito de colaboradores em diversas áreas. Há uma estrutura reduzida para atendimento da segurança e monitoramento patrimonial (atividades ilegais - invasão de gado, caçadores, pessoas); há lentidão nas respostas às demandas e ocorrências, no controle de incêndios, no controle de ações não autorizadas na UMF, etc. (SYSFLOR, 2015, p. 43).

Para garantir a certificação das áreas que forneceriam matéria-prima para a fábrica de celulose de Imperatriz, a Suzano realizou mudanças na gestão do Empreendimento de Manejo Florestal:

O EMF reestruturou a sua área de vigilância patrimonial com uma nova visão de negócio, criando área de Inteligência Patrimonial - IP. [...] Também, ao rever as responsabilidades dos supervisores operacionais, estes agora terão mais tempo disponível para cooperarem com as questões de segurança patrimonial da empresa. Outra decisão importante tomada foi a volta dos agentes florestais, com função específica de proteção patrimonial/florestal (SYSFLOR, 2016, p. 19).

Uma leitura mais crítica do relatório produzido pela SYSFLOR em 2016, e uma análise mais detalhada das ações tomadas pelo EMF para sanar os problemas operacionais, permitem aventar que as falhas estavam ligadas à otimização da mão-de-obra e à eliminação de postos de trabalhos - como os de agentes florestais.

Em 2018, a empresa utilizou aeronave para pulverizar as áreas de florestas plantadas com produtos químicos, mas não fez o levantamento e a análise dos impactos socioeconômicos que essa ação traria para as comunidades que seriam impactadas. Ao responder a certificadora porque não fez o levantamento socioeconômico, o EMF informou que "houve um aumento significativo nas aplicações aéreas na UNF-MA em virtude do aumento da base florestal (áreas da QG) e do ataque de pragas" (SYSFLOR, 2018, p. 69).

O parágrafo acima explicita mais uma vez quais princípios regeram as ações operacionais da Suzano quando houve risco de perdas econômicas. Entre manter os princípios que norteiam a responsabilidade social e ambiental da empresa e o risco de 
| Implantação da fábrica de celulose da Suzano no sudoeste maranhense à luz dos princípios do desenvolvimento sustentável|

| Gabriel Nava Lima | Ademir Kleber Morbeck de Oliveira |

perdas econômicas, optou-se pela garantia dos ganhos econômicos em detrimento das comunidades. De acordo com Feil \& Schreiber (2017), existe o entendimento global que os conceitos de sustentabilidade e desenvolvimento sustentável devem fazer parte dos processos produtivos. Porém salientam que devido ao fator embrionário destes termos, que ainda carecerem de um conceito axiomático, ocorrem críticas e dúvidas em relação a aplicação teórica e prática destes conceitos.

\section{CONSIDERAÇÕES FINAIS}

No caso da expansão da fronteira agrícola no sudoeste maranhense, as contradições existentes entre o agronegócio e a agricultura de subsistência, principalmente na definição de como vai acontecer o uso e ocupação do solo, são a materialização das mudanças ocorridas no conceito de modernização do campo na sociedade capitalista. Sendo simplista, essas mudanças podem ser nomeadas como desmatamento, perda da biodiversidade, desemprego, pobreza e migração.

Fazer essa análise crítica é necessário, porque o processo de modernização do campo na região desqualificou o pequeno agricultor, lhe retirando, direta ou indiretamente, direitos básicos que deveriam ser garantidos pelo Estado. Além disso, o reordenamento fundiário ampliou a concentração de terras através do incentivo à produção de commodities do agronegócio e diminuiu a área destinada a agricultura familiar.

Entretanto, a territorialização foi vista por boa parte das comunidades que ficariam sob influência da Unidade Florestal da empresa como uma oportunidade de melhoria na qualidade de vida, pois criou expectativas ligadas ao desenvolvimento regional. A forma de uso e ocupação do solo seria mudada e ressignificada, mas as comunidades impactadas pelas mudanças seriam beneficiadas por ações sociais implementadas.

A Suzano usou o discurso de desenvolvimento sustentável para convencer a sociedade que seria impactada, que os ganhos sociais e econômicos dinamizariam a região e trariam mais investimentos, afirmando que a sua forma de produzir teria como pano de fundo a sustentabilidade e a responsabilidade social e ambiental.

A implantação de um empreendimento ligado ao agronegócio trará, sempre, algum tipo de impacto ambiental. Todavia, quando da sua implantação, são ressaltados e enaltecidos todos os possíveis ganhos sociais e econômicos que ele pode trazer para a região. Os impactos negativos são minimizados ou desconsiderados. Eles aparecem nas Análises de Impactos Ambientais e são descritos nos Relatórios de Impactos Ambientais, 
| Implantação da fábrica de celulose da Suzano no sudoeste maranhense à luz dos princípios do desenvolvimento sustentável|

| Gabriel Nava Lima | Ademir Kleber Morbeck de Oliveira |

mas a população só os percebe - na maioria das vezes - quando o processo de implantação já está em andamento, ou concluído.

A territorialização da Suzano no sudoeste do estado maranhense é uma realidade. O polo fabril e o Projeto Florestal modificaram permanentemente a forma de uso e ocupação do solo pela sociedade local. Por este motivo, é necessário compreender quais as consequências e estudar os impactos no meio socioeconômico que essa nova realidade representa, pois a ampliação das atividades produtivas fazem parte do planejamento da empresa para ampliar sua participação no mercado internacional de celulose, afirmando-se que todo o processo ocorre sob o prisma do desenvolvimento sustentável.

\section{REFERÊNCIAS}

ANDRADE, Maristela de Paula. (Coord.). Conflitos socioambientais no Leste Maranhense: problemas provocados pela atuação da Suzano Papel e Celulose e dos chamados gaúchos no Baixo Parnaíba. Relatório de Pesquisa. São Luís: GERUR/PPGCS/UFMA, 2012.

BECKER, Bertha Koiffmann. Revisão das políticas de ocupação da Amazônia: é possível identificar modelos para projetar cenários? Parcerias Estratégicas, Brasília, v. 6, n. 12, p. 135-159, 2001. Disponível em: <http://seer.cgee.org.br/index.php/parcerias estrategicas/ article/viewFile/178/172>. Acesso em: 01 out. 2018.

BRASIL. Instituto Brasileiro de Geografia e estatística. Atlas do Maranhão. Rio de Janeiro: IBGE, 1984.

CASTILLO, Ricardo. Dinâmicas recentes do setor sucroenergético no Brasil: competitividade regional e expansão para o bioma Cerrado. GEOgraphia, Niterói, n. 35, p. 95-119, 2015.

CIOFI, José Leandro. Uma investigação do nível de sustentabilidade das companhias de papel e celulose e a influência das informações financeiras sobre a qualidade da divulgação socioambiental. 2010. 110 f. Dissertação (Mestrado em Controladoria e Contabilidade) - Universidade de São Paulo, São Paulo, 2010.

FEIL, Alexandre André.; SCHREIBER, Dusan. Sustentabilidade e desenvolvimento sustentável: desvendando as sobreposições e alcances de seus significados. Cadernos EBAPE.BR, Rio de Janeiro, v. 15, n. 3, p. 667-681, 2017. Disponível em: $<$ https://www.scielo.br/pdf/cebape/v15n3/1679-3951-cebape-15-03-00667.pdf > . Acesso em: 01 out. 2018.

FERNANDES, Bernardo Mançano. Entrando nos territórios do Território. In: PAULINO, Eliane Tomiasi; FABRINI, João Edmilson. Campesinato e territórios em disputa. São Paulo: Expressão popular; UNESP: Programa de Pós-Graduação em Geografia, 2008. p. 273-302. 
| Implantação da fábrica de celulose da Suzano no sudoeste maranhense à luz dos princípios do desenvolvimento sustentável|

| Gabriel Nava Lima | Ademir Kleber Morbeck de Oliveira |

FERNANDEZ, Brena Paula Magno. Ecodesenvolvimento, Desenvolvimento Sustentável e Economia Ecológica: em que sentido representam alternativas ao paradigma de desenvolvimento tradicional? Desenvolvimento e Meio Ambiente, Curitiba, n. 23, p. 109-120, 2011. Disponível em: < https://revistas.ufpr.br/made/article/view/19246/14460>. Acesso em: 01 out. 2018.

FERREIRA, Maria da Glória Rocha. (Re) organização do espaço a partir da produção de soja: Balsas - MA. Terra Livre, Presidente Prudente, v. 2, n. 27, p. 149-164, 2006. Disponível em: <https://www.agb.org.br/publicacoes/index.php/terralivre/article/view/414/393 >. Acesso em: 01 out. 2018.

FERREIRA, Antônio José de Araújo. Políticas territoriais e a reorganização do espaço maranhense. 2008. 269 f. Tese (Doutorado em Geografia Humana) - Universidade de São Paulo, São Paulo, 2008.

FIALHO, Francisco Antônio Pereira; MACEDO, Marcelo; MONTIBELLER, Gilberto; MITIDIERI, Tibério da Costa. Empreendedorismo na era do conhecimento. Florianópolis: Visual Books, 2007.

FIGUEIREDO, Admam Hama. Formação Territorial. In: FIGUEIREDO, Admam Hama (Org.). Brasil: uma visão geográfica e ambiental no início do século XXI. Rio de Janeiro: IBGE, Coordenação de Geografia, 2016. p. 9-38.

FREEMAN, R. Edward; McVEA, John F. A stakeholder approach to strategic management. In: HITT, Michael A.; FREEMAN, R. Edward.; HARRISON, Jeffrey S. Handbook of strategic management. Oxford: Blackwell Publishing, 2000. p. 189-207.

IBGE. Instituto Brasileiro de Geografia e Estatística. Sinopse do Senso Demográfico de 2010. Disponível em: < https://censo2010.ibge.gov.br/sinopse/index.php?dados=8>. Acesso em: 09 de jul.2019.

IBGE. Instituto Brasileiro de Geografia e Estatística. Cidades e Estados. Disponível em: < https://www.ibge.gov.br/cidades-e-estados/ma.html>. Acesso em: 23 de ago. 2019.

KELLER, Francisca Isabel Vieira. O homem da frente de expansão: permanência, mudança e conflito. Revista de História, São Paulo, v. 51, n. 102, p. 665-709, 1975. Disponível em: < http://www.revistas.usp.br/revhistoria/article/view/132957/129010>. Acesso em: out. 2018.

LABTRANS. Plano Mestre Porto do Itaqui. Elaboração: Laboratório de Transporte e Logística. Florianópolis: UFSC, 2015.2 Disponível em: $<$ http://www.portodoitaqui.ma.gov.br/pdf/plano-mestre-porto\%20do-itaqui.pdf $>$.

Acesso em: 20 set. 2019.

LINDBLOM, C. K. The implications of organizational legitimacy for corporate social performance and disclosure. In: GRAY, Rob; BEBBINGTON, Jan; GRAY, Sue. Social and environmental accounting. Los Angeles: SAGE, 2010. p. 51-63.

MARQUES, Marta Inez Medeiros. A Territorialização da Empresa Suzano no campo em São Paulo e no Maranhão. Revista GeoNordeste, São Cristóvão, v. 27, n. 2, p. 213-227, 
| Implantação da fábrica de celulose da Suzano no sudoeste maranhense à luz dos princípios do desenvolvimento sustentável|

| Gabriel Nava Lima | Ademir Kleber Morbeck de Oliveira |

2016. Disponível em: <https://seer.ufs.br/index.php/geonordeste/article/view/6160>. Acesso em: 01 out. 2018.

MENEZES, Marilda; MALAGODI, Edgard Afonso. Os camponeses como atores sociais: a perspectiva da autonomia e da resistência. In: SCHNEIDER, Sergio; GAZOLLA, Marcio (Org.). Os atores do desenvolvimento rural - perspectivas teóricas e práticas sociais. Porto Alegre: UFRGS, 2011. p. 49-66.

MIKHAILOVA, Irina. Sustentabilidade: evolução dos conceitos teóricos e os problemas da mensuração prática. Revista Economia e Desenvolvimento, Santa Maria, n. 16, p. 22 40, 2004. Disponível em: <https://periodicos.ufsm.br/eed/article/view/3442/1970>. Acesso em: out. 2018.

MOREIRA, Ruy. Geografia e práxis: a presença do espaço na teoria e na prática geográfica. São Paulo: Contexto, 2012.

ROCHA, Rosimary Gomes; MOTA, Francisco Lima. A inserção da economia maranhense no cenário nacional - o des(re)ordenamento territorial no sul do Maranhão. In: ENCONTRO NACIONAL DE GEOGRAFIA AGRÁRIA, 21., 2012, Uberlândia. Anais eletrônicos... Uberlândia: UFU/LAGEA, 2012. p. 1-20. Disponível em: $<$ http://www.lagea.ig.ufu.br/ xx1enga/anais enga 2012 /eixos/1196 1.pdf>. Acesso: 23 maio 2018.

OLIVEIRA, Allison Bezerra; PEREIRA, Jesus Marmanillo; NASCIMENTO, Amanda Araújo; Cadeia produtiva de papel e celulose e transformações recentes no sudoeste maranhense. InterEspaço: Revista de Geografia e Interdisciplinaridade, Grajaú, v. 4,

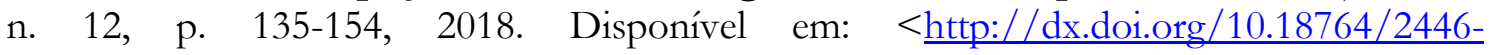
6549.v4n12p135-154>. Acesso em: 12 fev. 2019.

OLIVEIRA, Danniel Madson Vieira; RIBEIRO JUNIOR, José Arnaldo dos Santos. Desenvolvimento, conflitos e impactos ambientais: a territorialização da Suzano e a resistência camponesa na mesorregião Leste Maranhense. In: SIMPÓSIO INTERNACIONAL DE GEOGRAFIA AGRÁRIA, 6.; SIMPÓSIO NACIONAL DE GEOGRAFIA AGRÁRIA, 7.; JORNADA DE GEOGRAFIA DAS ÁGUAS, 1., 2013, João Pessoa. Anais... João Pessoa: UFPB, 2013. v. 1. p. 1-26.

PANTOJA, Vanda Maria Leite; PEREIRA, Jesus Marmanillo. Grandes projetos e populações tradicionais na Amazônia: a Suzano Papel e Celulose no Maranhão. Revista Política \&Trabalho, João Pessoa, n. 45, p. 327-340, 2016. Disponível em: $<$ http://periodicos.ufpb.br/ojs/index.php/politicaetrabalho/article/view/25862/17795 > . Acesso em: out. 2018.

PIRES, Elson Luciano da Silva; MÜLLER, Geraldo; VERDI, Adriana Renata. Instituições, territórios e desenvolvimento local: delineamento preliminar dos aspectos teóricos e morfológicos. Geografia, Rio Claro, v. 31, n. 3, p. 437-454, 2006. Disponível em: < http://www.periodicos.rc.biblioteca.unesp.br/index.php/ageteo/article/view/1374/206 4>. Acesso em: out. 2018.

PORRO, Roberto; MESQUITA, Benjamin Alvino; SANTOS, Itaan de Jesus Pastor. Expansão e trajetórias da pecuária na Amazônia: vales dos Rios Mearim e Pindaré Maranhão. Brasília: Ed. Universidade de Brasília, 2004. 
| Implantação da fábrica de celulose da Suzano no sudoeste maranhense à luz dos princípios do desenvolvimento sustentável|

| Gabriel Nava Lima | Ademir Kleber Morbeck de Oliveira |

RIBEIRO JÚNIOR, José Arnaldo dos Santos; OLIVEIRA, Danniel Madson Vieira; COSTA, Saulo Barros. Desenvolvimento, conflitos e impactos ambientais: a territorialização da Suzano e a resistência camponesa na mesorregião do Leste Maranhense. Geographia Opportuno Tempore, Londrina, v. 1, n. 2, p. 11-33, 2014. Disponível em: <http://www.uel.br/revistas/uel/index.php/Geographia/article/view/17887/15368>.

Acesso em: 01 out. 2018.

SACHS, Ignacy. Espaços, tempos e estratégias do desenvolvimento. São Paulo: Vértice, 1981.

SANTOS, Milton. Metamorfoses do espaço habitado: fundamentos teóricos e metodológicos da Geografia. São Paulo: Hucitec, 1996.

SANTOS, Frednan Bezerra; TAVARES, João Claudino. Questão agrária e violência no Maranhão: grilagem, colonização dirigida e a luta dos trabalhadores. Revista de Políticas Públicas, São Luís, v. 20, n. 1, p. 361-382, 2016. Disponível em: $<\underline{\text { http://www.periodicoseletronicos.ufma.br/index.php/rppublica/article/view/5061/311 }}$ 7>. Acesso em: out. 2018.

SANTOS, Raimundo Lima. O Projeto Grande Carajás e suas consequências para as populações extrativistas do Maranhão. Imperatriz: Ética, 2011.

SCHNEIDER, Sérgio. Teoria social, agricultura familiar e pluriatividade. Revista Brasileira de Ciências Sociais, São Paulo, v. 18, n. 51, p. 99-121, 2003. Disponível em: $<$ https://www.scielo.br/pdf/rbcsoc/v18n51/15988.pdf>. Acesso em: 01 out. 2018.

STPC. STCP Engenharia de Projetos Ltda. Relatório de Impacto Ambiental - Rima da área de implantação do projeto florestal da Suzano na região de Porto Franco, Maranhão. Curitiba: STCP Engenharia de Projetos Ltda, 2010. Disponível em: $<$ https://docplayer.com.br/3009695-Relatorio-de-impacto-ambiental-rima-da-area-deimplantacao-do-projeto-florestal-da-suzano-na-regiao-de-porto-franco-estado-domaranhao.html >. Acesso em: 30 out. 2016.

SUZANO. Suzano Papel e Celulose. Sustentabilidade. Disponível em: < http://ri.suzano.com.br/a-companhia/sustentabilidade>. Acesso em: 21 jan. 2020.

SUZANO. Suzano Papel e Celulose. Relatório de Sustentabilidade 2019. Suzano, 2020. Disponível em: < https://www.suzano.com.br/r2019/>. Acesso em: 01 maio 2020.

SYSFLOR. Sysflor Certificações de Manejo e Produtos Florestais. Relatório da avaliação fase 2 para certificação de manejo florestal e cadeia de custódia desde a floresta até a saída do produto da empresa - Suzano Papel e Celulose S.A. - UNF MA. Curitiba: SYSFLOR, 2013. Disponível em: <http://www.sysflor.com.br/contentdownloads/resumo-publico-do-relatorio-da-auditoria-de-certificacao-fase-2-de-2013-dasuzano-papel-e-celulose-s-a-unf-maranhao >. Acesso em: 28 nov. 2019.

SYSFLOR. Sysflor Certificações de Manejo e Produtos Florestais. Relatório de auditoria anual do manejo das plantações florestais e da cadeia de custódia desde a floresta até a saída do produto da empresa. Suzano Papel e Celulose S.A. - UNF MA. Curitiba: SYSFLOR, 2014. Disponível em: <http://www.sysflor.com.br/contentdownloads/resumo-publico-do-relatorio-da-auditoria-de-supervisao-de-2014-da-suzanopapel-e-celulose-s-a-unf-maranhao >. Acesso em: 28 nov. 2019. 
| Implantação da fábrica de celulose da Suzano no sudoeste maranhense à luz dos princípios do desenvolvimento sustentável|

| Gabriel Nava Lima | Ademir Kleber Morbeck de Oliveira |

SYSFLOR. Sysflor Certificações de Manejo e Produtos Florestais. Relatório de auditoria anual do manejo das plantações florestais e da cadeia de custódia desde a floresta até a saída do produto da empresa. Suzano Papel e Celulose S.A. - UNF MA. Curitiba: SYSFLOR, 2015. Disponível em: < $\underline{\text { http://www.sysflor.com.br/content- }}$ downloads/sumario-da-auditoria-especial-de-2015-da-suzano-papel-e-celulose-s-a-unfmaranhao >. Acesso em: 28 nov. 2019.

SYSFLOR. Sysflor Certificações de Manejo e Produtos Florestais. Relatório de auditoria anual do manejo florestal e da cadeia de custódia desde a floresta até a saída do produto da empresa. Suzano Papel e Celulose S.A. - UNF MA. Curitiba: SYSFLOR, 2016. Disponível em: <http://www.sysflor.com.br/content-downloads/resumo-publicodo-relatorio-da-auditoria-de-supervisao-de-2016-da-suzano-papel-e-celulose-s-a-unfmaranhao >. Acesso em: 28 de nov. 2019.

SYSFLOR. Sysflor Certificações de Manejo e Produtos Florestais. Relatório de auditoria anual do manejo florestal e da cadeia de custódia desde a floresta até a saída do produto da empresa. Suzano Papel e Celulose S.A. - UNF MA. Curitiba: SYSFLOR, 2017. Disponível em: < http://www.sysflor.com.br/content-downloads/resumo-publicodo-relatorio-da-auditoria-de-supervisao-anual-de-2017-da-suzano-papel-e-celulose-s-a-unfmaranhao >. Acesso em: 28 nov. 2019.

SYSFLOR. Sysflor Certificações de Manejo e Produtos Florestais. Relatório da avaliação para recertificação de manejo florestal e cadeia de custódia desde a floresta até a saída do produto da empresa. Suzano Papel e Celulose S.A. - UNF Maranhão. Curitiba: SYSFLOR, 2018. Disponível em: <http://www.sysflor.com.br/contentdownloads/resumo-publico-do-relatorio-da-auditoria-de-recertificacao-de-2018-da-suzanopapel-e-celulose-s-a-unf-maranhao >. Acesso em: 28 nov. 2019.

Como citar este artigo:

\section{ABNT}

LIMA, G. N.; OLIVEIRA, A. K. M. de. Implantação da fábrica de celulose da Suzano no sudoeste maranhense à luz dos princípios do desenvolvimento sustentável. InterEspaço: Revista de Geografia e Interdisciplinaridade, v. 6, e202007, 2020. Disponível em: <http://dx.doi.org/10.18764/2446-6549.e202007>. Acesso em: 25 jan. 2020.

\section{APA:}

Lima, G. N., \& Oliveira, A. K. M. de. (2020). Implantação da fábrica de celulose da Suzano no sudoeste maranhense à luz dos princípios do desenvolvimento sustentável. InterEspaço: Revista de Geografia e Interdisciplinaridade, v. 6, e202007. Recuperado em 25 janeiro, 2020, de http://dx.doi.org/10.18764/2446-6549.e202007

\section{cc) creative}

This is an open access article under the CC BY Creative Commons 4.0 license.

Copyright (C) 2020, Universidade Federal do Maranhão.

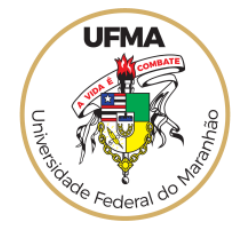

